\title{
Gelatin Zymography and Substrate Cleavage Assays of Matrix Metalloproteinase-2 in Breast Carcinoma Cells Overexpressing Membrane Type-1 Matrix Metalloproteinase
}

\author{
Boris I. Ratnikov, Elena I. Deryugina, and Alex Y. Strongin \\ The Burnham Institute, La Jolla, California
}

\begin{abstract}
SUMMARY: Gelatin zymography is the common method for examining matrix metalloproteinase-2 (MMP-2) in cells and media samples. Activation of the latent MMP-2 zymogen involves its binding to the cell surface MT1-MMP•TIMP-2 (membrane type-1 matrix metalloproteinase/tissue inhibitor of matrix metalloproteinase-2) complex with subsequent cleavage of proMMP-2 by TIMP-2-free adjacent MT1-MMP. This is followed by autolytic maturation of the activation intermediate and the release of the mature MMP-2 species from cell surfaces into the extracellular milieu. To observe the MMP-2 activation pathway in more detail, proMMP-2-deficient MCF7 breast carcinoma cells expressing MT1-MMP were incubated with excess proMMP-2 to saturate the available MT1-MMP•TIMP-2 surface receptors. After removal of the unbound material, the kinetics of proMMP-2 activation and MMP-2 release from cells into media was monitored by gelatin zymography and substrate cleavage. Our observations demonstrate that gelatin zymography is insufficient for providing meaningful information about the status of MMP-2. The proteolytically competent mature MMP-2 moiety alone, but not in its complex with TIMP-2, was released from the cells. In tissue culture conditions, the enzyme's proteolytic activity was suppressed in the next 30 to 60 minutes by tissue inhibitors of MMPs, especially by TIMP-1. The picture emerges that there is a likely temporal regulation of MMP-2 activity by TIMPs in tumor cells. These relatively rapid changes of the MMP-2 status cannot be detected by gelatin zymography. Additional studies are needed to examine the significance of this phenomenon in vivo. (Lab Invest 2002, 82:1583-1590).
\end{abstract}

$T$ he extracellular matrix turnover in tissues is largely initiated by matrix metalloproteinases (MMPs) (Nagase and Woessner, 1999; Sternlicht and Werb, 2001). Synthesized as inactive precursors, MMPs undergo proteolytic activation to exhibit enzymatic activity (Murphy et al, 1999). Activation, which may occur intracellularly and extracellularly, requires the cleavage of a prodomain located downstream of a signal peptide (Bassi et al, 2001; Pei and Weiss, 1995; Strongin et al, 1995; Van Wart and Birkedal-Hansen, 1990). The latency of MMP zymogens is maintained via coordination of the active site zinc by an unpaired cysteine sulfhydryl group within a PRCG(V/N)PD conserved sequence motif of the propeptide (Murphy et al, 1999; Nagase and Woessner, 1999; Van Wart and Birkedal-Hansen, 1990).

MMP-2 is secreted by many cell types and is the most abundant member of the MMP family. To exert its enzymatic activity, MMP-2 requires cleavage by

DOI: 10.1097/01.LAB.0000038555.67772.DB

Received August 22, 2002.

This work was supported by NIH Grants CA83017 and CA77470, California Breast Cancer Research Program Grant 5JB0094, and Susan G. Komen Breast Cancer Foundation Grant 9849 (all to AYS).

Address reprint requests to: Dr. A. Strongin, The Burnham Institute, 10901 North Torrey Pines Road, La Jolla, California 92037. E-mail: strongin@burnham.org membrane-tethered MT-MMPs, in particular membrane type-1 matrix metalloproteinase (MT1-MMP) (Deryugina et al, 2001; Sato et al, 1994; Seiki, 1999; Strongin et al, 1995). The expression of MT1-MMP and activation of MMP-2 have been shown to strongly correlate with tumor growth, neovascularization, and metastasis, making the MT1-MMP/MMP-2 system an attractive target for the prognosis and treatment of malignancies (Brooks et al, 1998; Deryugina et al, 1998; Hotary et al, 2000; Itoh et al, 1998a; McQuibban et al, 2000; Shankavaram et al, 2001).

The activity of MMPs is primarily regulated by four distinct tissue inhibitor of matrix metalloproteinases (TIMP-1 through TIMP-4) (Brew et al, 2000). Both activation and activity of MMP-2 are dependent on TIMP-2, which plays a dual role in MMP-2 activation (Shankavaram et al, 2001; Strongin et al, 1995). TIMP-2 inhibits MMP-2 by binding both its latent and activated forms (Goldberg et al, 1989; Nagase and Woessner, 1999; Strongin et al, 1993). In addition, TIMP-2 controls MMP-2 activation through its balance with MMP-2 and MT1-MMP (Strongin et al, 1995; Zucker et al, 1998). Thus, the N-terminal inhibitory domain of TIMP-2 (Higashi and Miyazaki, 1999; Miyazaki et al, 1993) binds the active site domain of MT1-MMP (the receptor) (Murphy et al, 1999; Shofuda et al, 1998; Strongin et al, 1995; Zucker et al, 1998). The exposed C-terminal domain of TIMP-2 then binds the TIMP-2-free MMP-2 proenzyme via the proen- 
zyme's C-terminal domain (Morgunova et al, 2002; Overall et al, 1999; Strongin et al, 1995) with subsequent activation of proMMP-2 by free adjacent MT1MMP (the activator). This cleavage converts the 68kDa MMP-2 proenzyme into the 64-kDa MMP-2 activation intermediate. Further, this intermediate autolytically matures into the fully active 62-kDa mature enzyme of MMP-2. Based on these concepts, both deficiency and excess TIMP-2 may inhibit MMP-2 activation.

Regardless of significant recent progress in MMP research, the regulatory mechanisms that govern cellsurface activation and activity of MMP-2 are not fully understood. Thus, some observations suggest that the functionally inactive MMP-2॰TIMP-2 complex, rather than the proteolytically competent MMP-2 species, is released from the trimolecular membranetethered MT1-MMP•TIMP-2॰MMP-2 activation ensemble (Itoh et al, 1998b). These and some other important observations concerning the role of TIMP-4 in the MT1-MMP-MMP-2 activation cascade and the role of TIMP-2 in the membrane type-2 matrix metalloproteinase-dependent activation of MMP-2 (Bigg et al, 2001; Morrison et al, 2001) led us to re-examine the molecular mechanisms underlying the activation and the activity of MMP-2. Gelatin zymography has been the only method in the numerous publications used to examine MMP-2. In contrast, in our work we monitored both the activation and the activity of MMP-2 by a modified cell-based assay. This enabled us to elaborate the cellular mechanisms involved in the control of MMP-2 activity in more detail.

Here, we report that in cell culture conditions, the soluble activity of MMP-2 is rapidly repressed by TIMPs, thereby suggesting that there may be a temporal control of activated MMP-2 by TIMPs in vivo. It is tempting to hypothesize that shortly after the enzyme's release from the cell surface, the soluble MMP-2 activity in vivo is also controlled by TIMPs. It is likely that because of this regulation imposed by TIMPs, MMP-2 is involved in highly localized pericellular proteolysis in the cell vicinity rather than at a distance from cell surfaces.

\section{Results and Discussion}

\section{MMP-2 Activation by MCF7 Breast Carcinoma Cells Expressing MT1-MMP}

To analyze the mechanisms of MMP-2 activation, we used breast carcinoma MCF7 cells (Deryugina et al, 2001; Rozanov et al, 2001). Parental MCF7 cells are strongly deficient in both MT1-MMP and MMP-2. After transfection of these cells with the MT1-MMP cDNA, we selected the cells exhibiting relatively high levels of active MT1-MMP on the plasma membrane (MT cells) (Deryugina et al, 2001). These cells have been demonstrated to efficiently activate the exogenous 68-kDa MMP-2 proenzyme generating the 62-kDa mature enzyme of MMP-2. In the MCF7 cell system, TIMP-2 is present in amounts sufficient to promote rapid activation of exogenous MMP-2 (Deryugina et al, 2001;
Rozanov et al, 2001). Importantly, as shown earlier by gelatin zymography (Rozanov et al, 2001), there are no naturally secreted gelatinolytically active proteinases, such as the 82- to 92-kDa MMP-9 enzyme/proenzyme and the high molecular weight complexed gelatinases, with a molecular weight higher than $110 \mathrm{kDa}$ in serumfree media conditioned by parental, control, or MT1MMP-transfected MCF7 cells (Deryugina et al, 2001). Consequently, no proteases could interfere with exogenous MMP-2 in our activity studies.

To more accurately examine the mechanisms of MMP-2 activation by cells and to avoid undesirable effects of any traces of activated MMP-2 and TIMPs, which may be present in the purified proMMP-2 samples, we modified the MMP-2 activation cell assay. In this study, cells were incubated with excess latent zymogen to saturate the available MT1-MMP•TIMP-2 surface receptors. Next, the cells were washed to remove any unbound material including proMMP-2, MMP-2 enzyme, and TIMPs. This significantly reduced the background activity of MMP-2 and allowed us to examine in greater detail the mechanisms involving MT1-MMP, TIMP-2, and TIMP-1 in the activation and regulation of the MMP-2 function. Further, the cell-associated and soluble activity of MMP-2 was estimated using biotin-labeled gelatin as substrate. This method was described in detail earlier (Ratnikov et al, 2000). Briefly, gelatin (denatured collagen type I) is the most common and inexpensive protein substrate highly susceptible to cleavage by gelatinases including MMP-2 and less efficiently by other MMPs. This is the reason we chose this substrate for our studies. To provide a sensitive detection system for the assay, gelatin was labeled with biotin. Because the frequency of lysine residues in collagen type I sequence is much lower relative to that of the consensus PXGX cleavage sites for MMPs, the majority of the resulting proteolytic fragments should be devoid of biotin. Streptavidin-coated 96-well plates were used to capture the biotin-containing fragments generated by the proteolytic degradation of biotinylated gelatin (BG) with MMPs. The captured fragments were revealed with streptavidin-horseradish peroxidase (HRP). The HRP activity was measured by using a standard colorimetric substrate for this enzyme. Proteolytic fragments with no biotin label cannot bind to plastic coated with streptavidin, whereas fragments with a single biotin moiety capable of binding to streptavidin-coated wells are not identifiable because they miss the second biotin residue essential for the binding of streptavidin-HRP. Therefore, only the fragments with at least two biotin residues are detectable in our assay.

Both conditioned media and cell lysates were analyzed for the presence of gelatinolytically active proenzyme, intermediate, and mature forms of MMP-2. Although zymography was used to assess the activation status and relative amounts of the MMP-2 forms, the cleavage of BG was used to measure the functional activity of the MMP-2 enzyme. 


\section{Active Soluble MMP-2 Is Released from the Cells}

As demonstrated by gelatin zymography, exogenous proMMP-2 was efficiently activated by the MT cells. The activated enzyme was released from the cells into the medium. Control mock-transfected cells failed to induce activation of proMMP-2 and its conversion to the 62-kDa enzyme (Fig. 1A).

To analyze the kinetics of MMP-2 activation, we saturated the available cell receptors by preincubating cells for 1 hour with excess exogenous proMMP-2, washed cells to remove the unbound material, and replenished cells with fresh BSA/DMEM (time zero). To

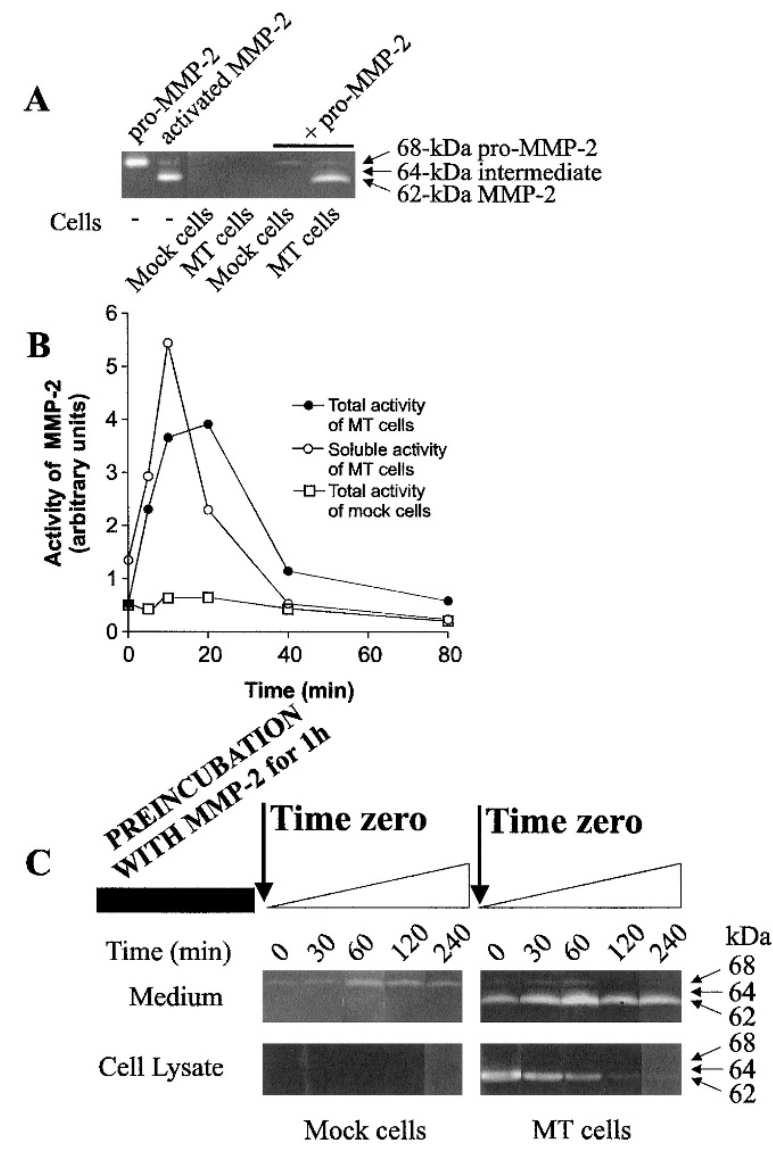

Figure 1.

MCF7 cells expressing membrane type-1 matrix metalloproteinase (MT1MMP) activate promatrix metalloproteinase-2 (MMP-2). MCF7 control (mock) and MT cells were preincubated with proMMP-2 $(5 \mu \mathrm{g} / \mathrm{ml})$ for 1 hour. Next, the cells were extensively washed and replenished with BSA/DMEM. At the indicated times, the status of soluble MMP-2 released from the cells into the medium (Medium) and cell-associated MMP-2 (Cell Lysate) was assessed by gelatin zymography. The soluble and total (ie, soluble plus cell-associated) gelatinolytic activity of the samples was examined as described in "Materials and Methods." A, MT cells activate exogenous proMMP-2. Mock and MT cells were preincubated with or without proMMP-2 and then transferred to fresh medium. In 4 hours, the medium conditioned by cells was analyzed by gelatin zymography. Purified proMMP-2 and the active MMP-2 enzyme are shown as reference. No MMP-2 was observed in mock and MT cells preincubated without exogenous proMMP-2. B. The gelatinolytic activity of the MMP-2 samples from mock and MT cells. C, Time course of proMMP-2 activation and release by MT cells. Aliquots of appropriately diluted conditioned media and cell lysates were loaded on gelatin gels at $10 \mu \mathrm{l}$ and at an equivalent of $10^{5}$ cells per lane, respectively. To generate the comparable gelatinolytic bands, the 240-minute sample of MMP-2 was further 9-fold diluted relative to the 10-minute sample. assess a time-dependent conversion and the release of the activated MMP-2 enzyme by the cells, the aliquots of medium and cells were examined both by gelatin zymography and by the cleavage of the BG substrate (Fig. 1B). Alternatively, BG was directly added to the cells to evaluate the total capacity of both cell-associated and soluble MMP-2 activity to cleave the BG substrate.

No MMP-2 was detected in the cell lysates of control cells, whereas low levels of soluble proMMP-2 were detected in conditioned medium. In contrast, during a 1-hour preincubation with proMMP-2, the MT cells have already fully converted the proenzyme into active MMP-2, thus exhibiting significant quantities of both the cell-associated and soluble MMP-2 enzyme at time zero. The amounts of cell-associated enzyme in MT cells gradually decreased, suggesting its release from the MT1-MMP-TIMP-2 cell surface complexes into conditioned medium. In agreement, high levels of soluble MMP-2 were detected in the medium samples of MT cells. Generally, these observations suggest that at time zero, the vast majority of proMMP-2 is already converted to the active form. It is well known that active MMP-2 may be subjected to autolysis. Autolysis routinely generates the central $45-\mathrm{kDa}$ gelatinolytically active fragment of the MMP-2 molecule as well as the catalytically inactive autolytic forms (Strongin et al, 1993). Because no characteristic 45$\mathrm{kDa}$ active autolytic form of MMP-2 was observed in our gelatin zymography assays, our data imply that there was no extensive autolytic degradation of MMP-2 in our cell system. Conversely, our observations imply that the loss of the soluble MMP-2 activity involves inhibition rather than autolysis. Additionally, because both soluble MMP-2 and TIMPs were lost after the washing step, the dominance of MMP-2 at early time points could not be attributed to the exclusive loss of TIMPs.

To corroborate these speculations, we monitored the proteolytic activity of cell-associated and released soluble MMP-2 (Fig. 1C). Surprisingly, the timedependent pattern of gelatinolytic activity in MT cells was strikingly different from what could have been expected from the zymography data. Thus, the activity of MMP-2 reached a maximum 15 to 20 minutes after replenishment of the cells with fresh medium and then sharply declined. After a 60-minute incubation of the MT cells in fresh medium, the net gelatinolytic activity was as low as the background values of the control cells. Furthermore, because activity levels of soluble MMP-2 were similar to those of total (ie, soluble plus cell-associated) activity of the enzyme, these observations provide evidence that the substrate was cleaved largely by the soluble enzyme released from the cells into medium. Because the gelatinolytic activity of MT1-MMP is at least 1000 -fold lower that that of MMP-2 (Ratnikov et al, 2000), the presence of MT1MMP in the MT cells did not interfere with the BG cleavage assay and did not generate any detectable gelatinolytic activity in our experimental conditions (data not shown). 
A transient gain and then rapid loss of soluble released MMP-2 activity suggest that MMP-2 is released from the cells in its active, mature form but promptly loses its proteolytic capacity in the medium. This implies that the soluble activity of MMP-2 is subjected to inhibition by TIMPs and this may lead to the formation of the MMP-2•TIMP stable complexes.

\section{Role of TIMP-1 in the Regulation of MMP-2 Activity}

To directly confirm that the medium conditioned by the cells can inhibit MMP- 2 activity, control cells $(2 \times$ $10^{5}$ ) were incubated in $0.5 \mathrm{ml}$ of BSA/DMEM for 18 hours. At the indicated time points, the aliquots $(0.5$ $\mathrm{ml}$ ) of medium were withdrawn to assess their inhibitory capacity against the active MMP-2 enzyme (3 ng) (Fig. 2A). The residual proteolytic activity of MMP-2 was examined using $B G$ as substrate. Figure $2 \mathrm{~A}$ demonstrates the presence of the inhibitory activity in the medium conditioned by control cells. The content of the inhibitors in a $0.5-\mathrm{ml}$ medium sample was sufficient to fully repress the activity of $3 \mathrm{ng}(0.05 \mathrm{pm})$ of active MMP-2 only after a 60-minute incubation of the cells in fresh medium, not at the earlier time points. These data strengthen the concept of temporal regulation of the MMP-2 activity.

To identify the nature of inhibitors associated with soluble MMP-2, we isolated MMP-2®inhibitor complexes from the medium. For these purposes, the MT and control cells $\left(1 \times 10^{8}\right.$ cells each) were incubated with excess proMMP-2. Then the unbound material was washed out and the cells were overlaid with $60 \mathrm{ml}$ of fresh BSA/DMEM. After 10 minutes and 240 minutes, the medium was collected and separated from cells by centrifugation. We expected these samples to provide us with the information regarding the transient status of MMP-2 shortly after its release from the cells (10 minutes) and about the stationary MMP-2/TIMP complexes (240 minutes). The MMP-2®inhibitor complexes were isolated by chromatography on a gelatinSepharose column. The eluted material was analyzed by immunoblotting using TIMP-1-specific or TIMP-2specific antibodies and by gelatin zymography and activity measurement using BG. Figure $2 \mathrm{~B}$ shows that the MMP-2 concentrations in the 10-minute and 240minute samples were about $2.5 \mu \mathrm{g} / \mathrm{ml}$ (40 pM) and $16.5 \mu \mathrm{g} / \mathrm{ml}$ (270 pм), respectively.

No activated MMP-2 was revealed in the medium conditioned by control cells. The levels of both TIMPs were very low in the 10-minute samples from the MT cells. In contrast, the levels of TIMP-1 in the 240minute samples from MT cells were high (about 7 $\mu \mathrm{g} / \mathrm{ml}, 230 \mathrm{pm}$ ), whereas the amounts of TIMP-2 were significantly lower (about $1 \mu \mathrm{g} / \mathrm{ml}, 45 \mathrm{pm}$ ). These data indicate that approximately $80 \%$ to $85 \%$ of soluble MMP-2 released by the MT cells was in a complex with TIMP-1, whereas about $15 \%$ to $20 \%$ of the enzyme was associated with TIMP-2. It has been established that TIMP-2 but not TIMP-1 is incapable of associating the latent zymogen of MMP-2 (Goldberg et al, 1989). Furthermore, TIMP-1 is known to be a poor inhibitor of MT1-MMP, whereas TIMP-2 is
A

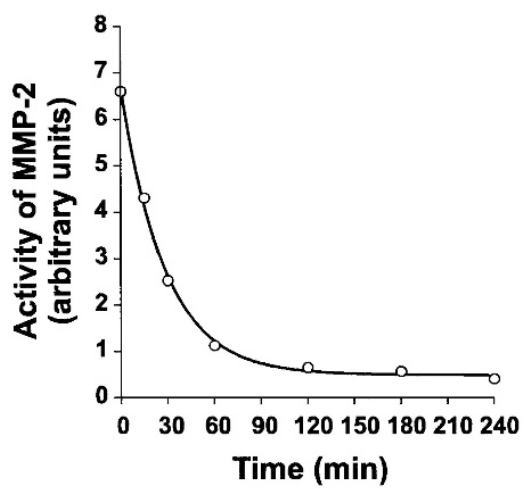

B

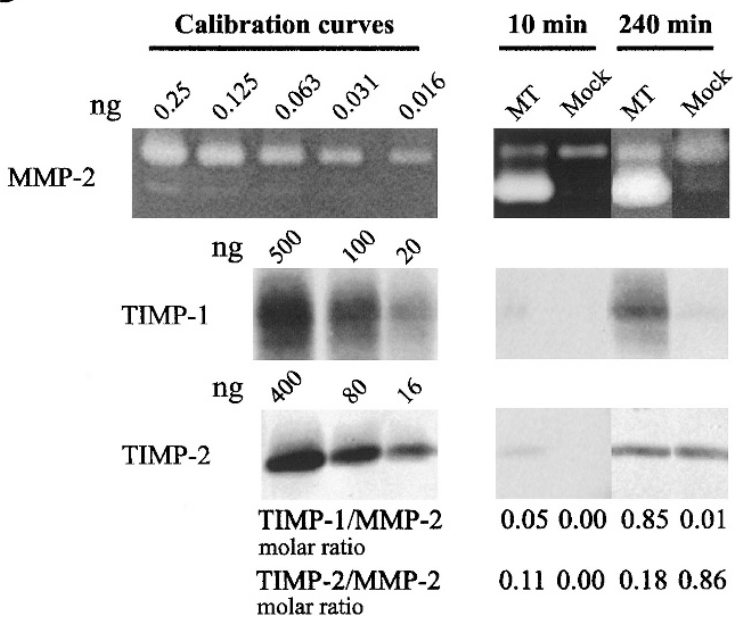

Figure 2.

TIMP-1 inhibits MMP-2 after the release of the mature active enzyme from the cells. A, MCF7 mock cells $\left(2 \times 10^{5}\right)$ were incubated in $0.5 \mathrm{ml}$ of BSA/DMEM for 18 hours. Aliquots $(0.5 \mathrm{ml})$ of medium were collected at the indicated time points and preincubated for 30 minutes with active MMP-2 ( $3 \mathrm{ng}$ in $0.5 \mathrm{ml}$ ). The residual gelatinolytic activity of MMP-2 was examined using biotinylated gelatin (BG) as substrate. B, Mock and MT cells were preincubated with 5 $\mu \mathrm{g} / \mathrm{ml}$ proMMP-2 for 1 hour. After washings to remove the unbound zymogen, cells were placed into fresh BSA/DMEM and incubated at $37^{\circ} \mathrm{C}$ for 10 minutes or 4 hours. Soluble MMP-2 released from cells into medium was isolated on a gelatin-Sepharose column. The eluates were dialyzed, concentrated, and tested for MMP-2 by gelatin zymography (upper panel) and for TIMP-1 and TIMP-2 by immunoblotting (middle and lower panels, respectively). The MMP-2 samples were appropriately diluted before loading on the gels, whereas the TIMP-1 and TIMP-2 samples were tested without any dilution. Concentrations of MMP-2 and TIMPs in the samples were calculated using the calibration curves that ranged from 0.008 to $0.5 \mathrm{ng} / \mathrm{ml}$ and from 10 to 500 $\mathrm{ng} / \mathrm{ml}$ of purified MMP-2 and TIMPs (TIMP-1 and TIMP-2), respectively. The molar ratio of the individual TIMPs to MMP-2 in the samples are shown at the bottom of the figure.

potent in inhibiting MT1-MMP (Will et al, 1996). Accordingly, excess TIMP-2 would fully inhibit activation of MMP-2 (Strongin et al, 1995; Zucker et al, 1998). In turn, TIMP-1 permits activation of MMP-2 by breast carcinoma cells and likely provides the mature enzyme with an opportunity to be active for a defined, relatively short period of time (Fig. 2B).

\section{The Status of Secretory MMP-2 Naturally Produced by U251 Glioma Cells}

To support these observations, we tested MMP-2 naturally produced by another cell type, glioma U251 cells (Deryugina et al, 1998). For these purposes, $10^{7}$ 


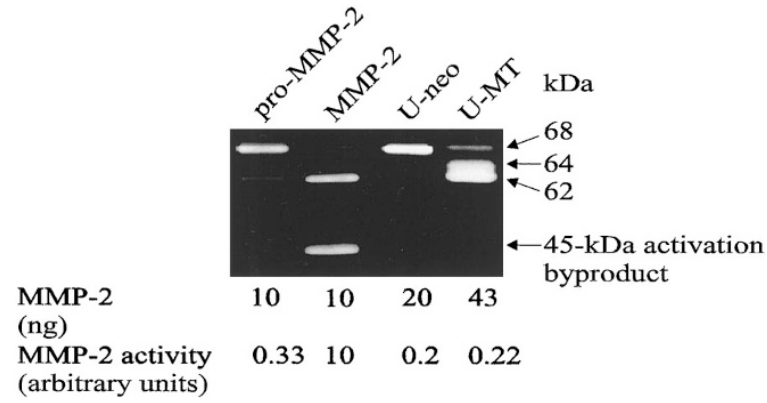

Figure 3.

Naturally synthesized MMP-2 does not exhibit any proteolytic activity in U251 glioma cells. Aliquots of purified proMMP-2 $(10 \mathrm{ng} / \mathrm{ml})$, aminophenylmercuric acetate (APMA)-activated MMP-2 $(10 \mathrm{ng} / \mathrm{ml})$, and media conditioned by U-neo cells $(20 \mathrm{ng} / \mathrm{ml}$ of MMP-2) and U-MT cells $(43 \mathrm{ng} / \mathrm{ml}$ of MMP-2) were appropriately diluted and analyzed by gelatin zymography. Proteolytic activity of the samples were determined by the BG cleavage assay and expressed in arbitrary units. MMP-2 concentration in the samples was calculated using calibration curves that ranged from 0.008 to $0.5 \mathrm{ng} / \mathrm{ml}$ (data not shown). Note the absence of MMP-2 activity of the U-MT sample, which has high levels of the activated MMP-2 species.

cells were cultured into $6 \mathrm{ml}$ of fresh DMEM. After incubation for 18 hours, the concentrations, the activation status, and the proteolytic activity of soluble MMP-2 in media were evaluated by gelatin zymography and the activity assay (Fig. 3). The data were compared with the standard amounts $(10 \mathrm{ng} / \mathrm{ml})$ of the purified proMMP-2 zymogen and the aminophenylmercuric acetate (APMA)-activated MMP-2 enzyme. The enzymatic activity of purified proMMP-2 was very low and correlated with the amounts of mature MMP-2 observed in gelatin gels. After activation of proMMP-2 with APMA, the enzymatic activity of MMP-2 strongly increased. In agreement with our earlier studies, the mock cells (U-neo) secreted proMMP-2 (about $20 \mathrm{ng} / \mathrm{ml}$ per $10^{7}$ cells in 18 hours) but failed to activate the zymogen. According to zymography, U251 cells $\left(10^{7}\right)$ stably transfected with MT1-MMP (U-MT cells) produced about $40 \mathrm{ng} / \mathrm{ml}$ of MMP-2 and accomplished a significant conversion of proMMP-2 into the activated enzyme during an 18hour incubation. However, in 18 hours, no activated enzyme was catalytically active in U-MT cells. These observations support our data obtained with MCF7 breast carcinoma cells and clearly demonstrate that the use of gelatin zymography alone for evaluating MMP-2 could cause an erroneous assumption regarding the potential activity of the activated enzyme samples.

The present work demonstrates that the default pathway of the soluble MMP-2 activity is to be inhibited by TIMPs (primarily, by TIMP-1 in MCF7 cells) shortly after the enzyme's release from the MT1MMP•TIMP-2 cellular receptors. In agreement, stimulation of many cell types with phorbol esters stimulated activation of naturally secreted proMMP-2 and the synthesis of TIMP-1 but not TIMP-2 (Lim et al, 1996; Mackay et al, 1992). Our results suggest that the active MMP-2 enzyme is likely to be capable of highly localized pericellular proteolysis. According to our model, there is a low probability that MMP-2 exists in its proteolytically active form at a distance from the cell surface. It is well known that an imbalance between proteinases and their inhibitors, in particular between TIMPs and MMPs, can contribute to tumorigenesis. The knowledge about regulation of MMP-2 activity is critically important for developing better diagnostic and prognostic methods and for efficient therapeutics capable of manipulating the MMP-2 activity in a clinically advantageous manner. The tissue culture results presented in our report may provide new insights into the temporal and spatial regulation of MMP-2 in vivo.

\section{Materials and Methods}

\section{Reagents and Proteins}

ProMMP-2 free from TIMP-2 was isolated from conditioned medium of p2AHT2A72 cells derived from an HT-1080 fibrosarcoma cell line sequentially transfected with E1A and MMP-2 cDNAs (Strongin et al, 1993, 1995). TIMP-1 and TIMP-2 were purchased from Fuji Chemical Industries (Tokyo, Japan). Rabbit antibody AB800 specific to TIMP-1 and T8062 specific to TIMP-2 were from Chemicon (Temecula, California) and Sigma (St. Louis, Missouri), respectively. The MCF7 cell line stably expressing human MT1-MMP (MT cells) and a control cell line transfected with the original vector alone (control mock cells) were described previously (Deryugina et al, 2001; Rozanov et al, 2001). U251 glioma cells stably transfected with the original vector or the vector encoding MT1-MMP were isolated and extensively characterized in our previous publications (Deryugina et al, 1997a, 1997b, 1998). Gelatin-Sepharose was from Amersham-Pharmacia (Piscataway, New Jersey). DMEM, FCS, and antibiotics were from Invitrogen (San Diego, California).

\section{Cell Culture and Hydrolysis of BG}

Cells were plated in DMEM supplemented with $10 \%$ FCS (DMEM/FCS) at $2.5 \times 10^{5}$ cells/well in a 48-well plate (Costar, Cambridge, Massachusetts). After an overnight incubation, cells were washed with serumfree DMEM and then incubated for 1 hour with excess proMMP-2 (750 $\mathrm{ng}$ in $0.15 \mathrm{ml}$ of serum-free DMEM; about a 300 -fold molar excess relative to the total amount of cell surface MT1-MMP in these cells) to saturate the existing cell surface TIMP-2•MT1-MMP complexes. Next, the cells were extensively washed with DMEM and $0.1 \%$ BSA/DMEM to remove soluble unbound proMMP-2. BG was added from the stock solution to each well $(75 \mathrm{ng} \mathrm{BG}$ in $0.5 \mathrm{ml}$ of $0.1 \%$ BSA/DMEM) to monitor the activity of cell surfaceassociated MMP-2. After incubation at $37^{\circ} \mathrm{C}$ for 5 to 240 minutes, aliquots were taken from each well, mixed with EDTA to inactivate MMP-2, and spun to remove cells. Further, the amounts of degraded BG were quantified in each sample as described earlier (Ratnikov et al, 2000). Briefly, $100-\mu l$ samples were transferred to wells of streptavidin-coated microtiter plates. Before the experiments, microtiter plates were blocked with $1 \%$ casein in PBS for 30 minutes at 
$37^{\circ} \mathrm{C}$. After incubation with the samples for 30 minutes at $37^{\circ} \mathrm{C}$, plates were extensively washed with PBS-0.05\% Tween 20 and further incubated for 30 minutes at $37^{\circ} \mathrm{C}$ with streptavidin-HRP diluted $1: 10,000$ in the same buffer. It has been previously shown that there is no displacement of BG fragments by streptavidin-HRP in the streptavidin-coated plates. Because streptavidin and streptavidin-HRP exhibit similar affinities to biotin, no competition for binding of BG fragments containing two or more biotins by the coated streptavidin (which exists in excess in coated plates relative to streptavidin-HRP) and streptavidinHRP has been found in our assay system (Ratnikov et al, 2000). After extensive washing with PBS-0.05\% Tween 20, the HRP activity was revealed with 100 $\mu \mathrm{l} /$ well of TMB/E (Chemicon) for 3 to 5 minutes. The reaction was stopped by adding $50 \mu \mathrm{l} /$ well of $1 \mathrm{~N} \mathrm{HCl}$. The plate was read at $450 \mathrm{~nm}$ in a microtiter plate reader.

Alternatively, to measure the soluble activity of MMP-2, cells were incubated for 1 hour with excess proMMP-2 (750 ng in $0.15 \mathrm{ml}$ serum-free DMEM), washed to remove unbound proteins, and further incubated in BSA/DMEM (0.5 ml/well). In 5 to 240 minutes, aliquots $(0.5 \mathrm{ml}$ each) were taken and spun to remove the cells, and the supernatants were mixed with the substrate stock to reach $75 \mathrm{ng} \mathrm{BG}$. The samples were incubated for 4 hours at $37^{\circ} \mathrm{C}$ to allow hydrolysis of $B G$. The reactions were stopped with EDTA (final concentration of $20 \mathrm{~mm}$ ). The amounts of degraded $B G$ were quantified in each sample as described above.

The resulting activity values were compared with the activity of purified TIMP-2-free proMMP-2 activated by APMA. For these purposes, proMMP-2 was treated with $2 \mathrm{~mm}$ APMA at $25^{\circ} \mathrm{C}$ for 1 hour in $5 \mathrm{~mm}$ Tris- $\mathrm{HCl}$, $\mathrm{pH} 7.5,0.1 \mathrm{~mm} \mathrm{CaCl}_{2}$, and $0.005 \%$ Brij 35. The activation of proMMP-2 was monitored by gelatin zymography. Further, the activated enzyme was appropriately diluted with $50 \mathrm{~mm}$ Tris- $\mathrm{HCl}, 150 \mathrm{~mm} \mathrm{NaCl}$, $5 \mathrm{mM} \mathrm{CaCl}_{2}$, and $0.005 \%$ Brij 35 and its activity was estimated in gelatinase activity assay using BG as substrate.

\section{Gelatin Zymography}

Aliquots of cell lysates and medium conditioned by cells were analyzed by gelatin zymography in $0.1 \%$ gelatin-10\% acrylamide gels (Deryugina et al, 2001). Cells were lysed in SDS-sample buffer. Aliquots of appropriately diluted media and cell lysate were loaded without reduction on gels at $10 \mu \mathrm{l}$ and at an equivalent of $10^{5}$ cells per lane, respectively. After electrophoresis, gels were washed with $2.5 \%$ Triton $\mathrm{X}-100$ to remove SDS and renature the MMP-2 species in the gels. Then the gels were incubated in the developing buffer overnight to induce gelatin lysis by renatured MMP-2. MMP-2 concentrations in the cell and media samples were calculated by gelatin zymography using the calibration curves that ranged from 0.008 to $0.5 \mathrm{ng} / \mathrm{ml}$ of the purified MMP-2 proenzyme (Leber and Balkwill, 1997; Oliver et al, 1997).

\section{Quantification of MMP-2॰TIMP-1 and MMP-2॰TIMP-2 Complexes}

Cells $\left(10^{8}\right)$ were grown in DMEM/FCS to confluence and then washed with serum-free DMEM. Then cells were incubated at $37^{\circ} \mathrm{C}$ for 1 hour in $60 \mathrm{ml}$ serum-free DMEM supplemented with $5 \mu \mathrm{g} / \mathrm{ml}$ proMMP-2. To remove unbound MMP-2, cells were washed with serum-free DMEM and BSA/DMEM. Next, cells were incubated in $60 \mathrm{ml}$ BSA/DMEM, and conditioned medium was collected after 10 and 240 minutes. MMP-2 was isolated from media on a $0.5 \mathrm{ml}$ gelatinSepharose column. To remove impurities, the column was washed with $50 \mathrm{~mm}$ Tris- $1.5 \mathrm{M} \mathrm{NaCl}$ buffer, $\mathrm{pH}$ 7.5. The bound MMP-2 was eluted with $2.5 \mathrm{ml}$ of the above buffer supplemented with $10 \%$ dimethyl sulfoxide. The eluate was dialyzed against $5 \mathrm{~mm}$ Tris$0.005 \%$ Brij 35 buffer, pH 7.5. Dialyzed samples (total volume $2.5 \mathrm{ml}$ ) were concentrated 125-fold on a Speed VAC. MMP-2 and both TIMP-1 and TIMP-2 were quantified by gelatin zymography and Western blotting, respectively. The concentrations of MMP-2, TIMP-1, and TIMP-2 in the purified samples were assessed by comparing the intensity of the bands with that of serially diluted respective purified standards. The concentrations of TIMP-2 and TIMP-1 in the samples were monitored by immunoblotting and calculated using the calibration curves that ranged from 10 to $500 \mathrm{ng} / \mathrm{ml}$ of the purified respective proteins. Immunoblotting was performed as described (Deryugina et al, 2001) using rabbit antibody $A B 800$ and T8062 against TIMP-1 and TIMP-2, respectively. The bands were visualized using goat anti-rabbit IgG conjugated with HRP and TMB/M substrate (Chemicon).

\section{References}

Bassi DE, Lopez De Cicco R, Mahloogi H, Zucker S, Thomas G, and Klein-Szanto AJ (2001). Furin inhibition results in absent or decreased invasiveness and tumorigenicity of human cancer cells. Proc Natl Acad Sci USA 98:1032610331.

Bigg HF, Morrison CJ, Butler GS, Bogoyevitch MA, Wang Z, Soloway PD, and Overall CM (2001). Tissue inhibitor of metalloproteinases-4 inhibits but does not support the activation of gelatinase A via efficient inhibition of membrane type 1-matrix metalloproteinase. Cancer Res 61:3610-3618.

Brew K, Dinakarpandian D, and Nagase H (2000). Tissue inhibitors of metalloproteinases: Evolution, structure and function. Biochim Biophys Acta 1477:267-283.

Brooks PC, Silletti S, von Schalscha TL, Friedlander M, and Cheresh DA (1998). Disruption of angiogenesis by PEX, a noncatalytic metalloproteinase fragment with integrin binding activity. Cell 92:391-400.

Deryugina El, Bourdon MA, Luo GX, Reisfeld RA, and Strongin A (1997b). Matrix metalloproteinase-2 activation modulates glioma cell migration. J Cell Sci 110:2473-2482.

Deryugina El, Bourdon MA, Reisfeld RA, and Strongin A (1998). Remodeling of collagen matrix by human tumor cells requires activation and cell surface association of matrix metalloproteinase-2. Cancer Res 58:3743-3750. 
Deryugina El, Luo GX, Reisfeld RA, Bourdon MA, and Strongin A (1997a). Tumor cell invasion through matrigel is regulated by activated matrix metalloproteinase-2. Anticancer Res 17:3201-3210.

Deryugina El, Ratnikov B, Monosov E, Postnova TI, DiScipio R, Smith JW, and Strongin AY (2001). MT1-MMP initiates activation of pro-MMP-2 and integrin alphavbeta3 promotes maturation of MMP-2 in breast carcinoma cells. Exp Cell Res 263:209-223.

Goldberg GI, Marmer BL, Grant GA, Eisen AZ, Wilhelm S, and He CS (1989). Human 72-kilodalton type IV collagenase forms a complex with a tissue inhibitor of metalloproteases designated TIMP-2. Proc Natl Acad Sci USA 86:8207-8211.

Higashi S and Miyazaki K (1999). Reactive site-modified tissue inhibitor of metalloproteinases-2 inhibits the cellmediated activation of progelatinase A. J Biol Chem 274: 10497-10504.

Hotary K, Allen E, Punturieri A, Yana I, and Weiss SJ (2000). Regulation of cell invasion and morphogenesis in a threedimensional type I collagen matrix by membrane-type matrix metalloproteinases 1, 2, and 3. J Cell Biol 149:1309-1323.

Itoh $\mathrm{Y}$, Ito A, Iwata K, Tanzawa K, Mori $\mathrm{Y}$, and Nagase $\mathrm{H}$ (1998b). Plasma membrane-bound tissue inhibitor of metalloproteinases (TIMP)-2 specifically inhibits matrix metalloproteinase 2 (gelatinase A) activated on the cell surface. J Biol Chem 273:24360-24367.

Itoh T, Tanioka M, Yoshida H, Yoshioka T, Nishimoto H, and Itohara S (1998a). Reduced angiogenesis and tumor progression in gelatinase A-deficient mice. Cancer Res 58:10481051.

Leber TM and Balkwill FR (1997). Zymography: A single-step staining method for quantitation of proteolytic activity on substrate gels. Anal Biochem 249:24-28.

Lim YT, Sugiura Y, Laug WE, Sun B, Garcia A, and DeClerck YA (1996). Independent regulation of matrix metalloproteinases and plasminogen activators in human fibrosarcoma cells. J Cell Physiol 167:333-340.

Mackay AR, Ballin M, Pelina MD, Farina AR, Nason AM, Hartzler JL, and Thorgeirsson UP (1992). Effect of phorbol ester and cytokines on matrix metalloproteinase and tissue inhibitor of metalloproteinase expression in tumor and normal cell lines. Invasion Metastasis 12:168-184.

McQuibban GA, Gong JH, Tam EM, McCulloch CA, ClarkLewis I, and Overall CM (2000). Inflammation dampened by gelatinase A cleavage of monocyte chemoattractant protein-3. Science 289:1202-1206.

Miyazaki K, Funahashi K, Numata Y, Koshikawa N, Akaogi K, Kikkawa Y, Yasumitsu H, and Umeda M (1993). Purification and characterization of a two-chain form of tissue inhibitor of metalloproteinases (TIMP) type 2 and a low molecular weight TIMP-like protein. J Biol Chem 268:14387-14393.

Morgunova E, Tuuttila A, Bergmann U, and Tryggvason K (2002). Structural insight into the complex formation of latent matrix metalloproteinase 2 with tissue inhibitor of metalloproteinase 2. Proc Natl Acad Sci USA 99:7414-7419.

Morrison CJ, Butler GS, Bigg HF, Roberts CR, Soloway PD, and Overall CM (2001). Cellular activation of MMP-2 (gelatinase A) by MT2-MMP occurs via a TIMP-2-independent pathway. J Biol Chem 276:47402-47410.
Murphy G, Stanton H, Cowell S, Butler G, Knauper V, Atkinson S, and Gavrilovic J (1999). Mechanisms for pro matrix metalloproteinase activation. APMIS 107:38-44.

Nagase H and Woessner JF (1999). Matrix metalloproteinases. J Biol Chem 274:21491-21494.

Oliver GW, Leferson JD, Stetler-Stevenson WG, and Kleiner DE (1997). Quantitative reverse zymography: Analysis of picogram amounts of metalloproteinase inhibitors using gelatinase A and B reverse zymograms. Anal Biochem 244:161166.

Overall CM, King AE, Sam DK, Ong AD, Lau TT, Wallon UM, DeClerck YA, and Atherstone J (1999). Identification of the tissue inhibitor of metalloproteinases-2 (TIMP-2) binding site on the hemopexin carboxyl domain of human gelatinase $A$ by site-directed mutagenesis: The hierarchical role in binding TIMP-2 of the unique cationic clusters of hemopexin modules III and IV. J Biol Chem 274:4421-4429.

Pei D and Weiss SJ (1995). Furin-dependent intracellular activation of the human stromelysin-3 zymogen. Nature 375:244-247.

Ratnikov B, Deryugina E, Leng J, Marchenko G, Dembrow D, and Strongin A (2000). Determination of matrix metalloproteinase activity using biotinylated gelatin. Anal Biochem 286:149-155.

Rozanov DV, Deryugina El, Ratnikov BI, Monosov EZ, Marchenko GN, Quigley JP, and Strongin AY (2001). Mutation analysis of membrane type-1 matrix metalloproteinase (MT1MMP): The role of the cytoplasmic tail Cys-574, the active site Glu-240 and furin cleavage motifs in oligomerization, processing and self-proteolysis of MT1-MMP expressed in breast carcinoma cells. J Biol Chem 276:25705-25714.

Sato H, Takino T, Okada Y, Cao J, Shinagawa A, Yamamoto E, and Seiki M (1994). A matrix metalloproteinase expressed on the surface of invasive tumour cells. Nature 370:61-65.

Seiki M (1999). Membrane-type matrix metalloproteinases. APMIS 107:137-143.

Shankavaram UT, Lai WC, Netzel-Arnett S, Mangan PR, Ardans JA, Caterina N, Stetler-Stevenson WG, BirkedalHansen $\mathrm{H}$, and Wahl LM (2001). Monocyte membrane type 1-matrix metalloproteinase: Prostaglandin-dependent regulation and role in metalloproteinase-2 activation. J Biol Chem 276:19027-19032.

Shofuda K, Moriyama K, Nishihashi A, Higashi S, Mizushima $\mathrm{H}$, Yasumitsu H, Miki K, Sato H, Seiki M, and Miyazaki K (1998). Role of tissue inhibitor of metalloproteinases-2 (TIMP-2) in regulation of pro-gelatinase A activation catalyzed by membrane-type matrix metalloproteinase-1 (MT1MMP) in human cancer cells. J Biochem (Tokyo) 124:462470.

Sternlicht MD and Werb Z (2001). How matrix metalloproteinases regulate cell behavior. Annu Rev Cell Dev Biol 17:463516.

Strongin AY, Collier I, Bannikov G, Marmer BL, Grant GA, and Goldberg Gl (1995). Mechanism of cell surface activation of 72-kDa type IV collagenase: Isolation of the activated form of the membrane metalloprotease. J Biol Chem 270:53315338.

Strongin AY, Marmer BL, Grant GA, and Goldberg GI (1993). Plasma membrane-dependent activation of the 72-kDa type IV collagenase is prevented by complex formation with TIMP-2. J Biol Chem 268:14033-14039. 
Van Wart HE and Birkedal-Hansen H (1990). The cysteine switch: A principle of regulation of metalloproteinase activity with potential applicability to the entire matrix metalloproteinase gene family. Proc Natl Acad Sci USA 87:5578-5582.

Will H, Atkinson SJ, Butler GS, Smith B, and Murphy G (1996). The soluble catalytic domain of membrane type 1 matrix metalloproteinase cleaves the propeptide of progelatinase $A$ and initiates autoproteolytic activation: Regulation by TIMP-2 and TIMP-3. J Biol Chem 271:17119-17123.
Zucker S, Drews M, Conner C, Foda HD, DeClerck YA, Langley KE, Bahou WF, Docherty AJ, and Cao J (1998). Tissue inhibitor of metalloproteinase-2 (TIMP-2) binds to the catalytic domain of the cell surface receptor, membrane type 1-matrix metalloproteinase 1 (MT1-MMP). J Biol Chem 273: $1216-1222$. 